Case Report

\title{
A Comparative Study of the Oil-Free Centrifugal Water Chillers with the Flooded or Falling Film Evaporator-A Case Study
}

\author{
Kuo-Shu Hung ${ }^{1}$, Jenn-Chyi Chung ${ }^{1}$, Chung-Che Liu ${ }^{1}$, Jun-Jie Lin ${ }^{1}$ and Chi-Chuan Wang ${ }^{2, *(1)}$ \\ 1 Green Energy \& Environment Research Laboratories, Industrial Technology Research Institute, Chutung 310, Taiwan \\ 2 Department of Mechanical Engineering, National Chiao Tung University, Hsinchu 300, Taiwan \\ * Correspondence: ccwang@mail.nctu.edu.tw; Tel.: +886-3-5712121 (ext. 55105)
}

Received: 12 June 2019; Accepted: 1 July 2019; Published: 2 July 2019

\begin{abstract}
A comparative study regarding the performance of real-scale oil-free centrifugal chillers having the flooded evaporator or falling film evaporator was conducted in this study. The nominal capacity for the test chillers was around 200 230 USRT (US refrigeration ton) (703 809 kW). The compressors of the two chillers were identical and R-134a was used as the working fluid. Both evaporators employed the same enhanced tubes (GEWA-B) to fulfill phase change. Tests were conducted in full, $75 \%, 50 \%$, and $25 \%$ loading. Test results indicate that both chillers contained a comparable system performance with an integrated part-load value of around 8.62 8.63. The overall heat transfer coefficient for the flooded evaporator was appreciably higher $(20 \sim 40 \%)$ than the falling film evaporator. This is because the falling film flowrate was below the threshold value and the heat transfer was dominated by evaporation mode. Yet, the heat transfer performance for the falling film evaporator was further jeopardized due to starvation of the film flowrate (partial dry-out), especially in the middle or bottom of the tube bundle. This phenomenon became even more pronounced at partial loading $(25 \%)$, whereas the flooded evaporator did not reveal such a performance dip at partial loading.
\end{abstract}

Keywords: oil-free centrifugal chiller; flooded evaporator; falling film evaporator; heat transfer

\section{Introduction}

Normally, the designed cooling capacity of a water chiller for air-conditioning applications is based on the peak load demand. For large buildings, a centrifugal chiller is especially popular for large cooling capacity requirements. Yet, in subtropical or tropical zones, centrifugal chillers may work all year round. However, the full-load running period of the chiller is usually shorter than one month during a whole year operation, meaning that most of the time, chillers are in part-load operation [1]. Hence, for more effective characterization of a chiller in association with the part-load operation, implementation of integrated part-load value (IPLV) [2] is adopted as the design concept. The IPLV is defined as follows

$$
\mathrm{IPLV}=0.01 \mathrm{~A}+0.42 \mathrm{~B}+0.45 \mathrm{C}+0.12 \mathrm{D}
$$

where $\mathrm{A}$ is the coefficient of performance (COP) at $100 \%$ load, $\mathrm{B}$ is the COP at $75 \%$ load, $\mathrm{C}$ is the COP at $50 \%$ load, and D is the COP at $25 \%$ load. From Equation (1), the proportions of $75 \%$ and $50 \%$ part-loads are much higher than full-load or $25 \%$ load.

For effective part-load operation as far as cooling of commercial buildings is concerned, variable speed chillers are increasingly used in central air-conditioning systems, as they can effectively reduce electricity consumption. For conventional variable speed chillers, lubrication of the moving 
part is essential and oil circuits are used to lubricate the bearings and rotating parts. The problem of lubrication may even become severe at part-load operation due to loss of oil-return. As a consequence, appreciable frictional loss at the rotating shafts occurs and limits the high-speed operation. To tailor this problem, oil-free magnetic bearings that offer a contactless shaft subject to ultrahigh speed rotation are integrated with the compressors [3]. Yu et al. [4] reported an energy saving of $9.6 \%$ in the total electricity consumption in a shopping arcade by using oil-free chillers with variable speed control. An optimal control strategy for variable speed centrifugal compressors with magnetic bearings was developed by [5].

Note that the oil-free design not only contains a superior compressor efficiency under variable speed control but also can eliminate the heat transfer deterioration in evaporators [6,7]. For a typical centrifugal water chiller, the evaporator can be either flooded type or falling film type. The major heat transfer mechanism of flooded evaporator is via nucleate boiling, whereas the falling film evaporator makes use of both evaporation and nucleate boiling, and both designs incorporate effective phase-change processes. There were some related studies concerning the heat transfer regrading flooded evaporator or falling film evaporator; performances regarding single tube and tube bundle were reported [8-13] and some correlations were developed. Normally, the reported data have shown that the falling film design not only offers a less refrigerant inventory but also contains a higher heat transfer coefficient (HTC) when compared with the flooded evaporator $[12,14,15]$. However, these studies were based on reduced evaporator size with a much smaller bundle effect. Yet, heat transfer performance is not reported in a large chiller system. The only reported test results for a falling film evaporator in a real-scale large chiller were reported by Yang and Wang [16] and Yang et al. [17]. Yang and Wang [16] conducted heat transfer for falling film evaporators in large compression refrigeration systems via numerical study. They concluded that the mal distribution by the distributor could severely offset the performance of the falling film evaporator. Yang et al. [17] extended the numerical simulations to examine the influence of dry patch on the falling film evaporator and concluded that the heat transfer performance of falling evaporators can be enhanced by increasing the refrigerant flowrate within a certain range due to the decreasing dry patch areas on falling film tubes. Once the dry patches decrease to the minimum value of zero, the evaporators just reach the best thermal performance. Although their studies were applicable for a real-scale system, their main works focused on the numerical studies. Up to now, there were no comparative studies in real scale concerning the performance difference between a falling film evaporator and a flooded evaporator. Hence, the objective of this study is to provide quantitative comparisons from the perspective of system and heat transfer.

\section{Experimental Setup and Data Reduction for System Performance}

\subsection{Introduction to the Experimental Setup}

The schematic of the test chiller is shown in Figure 1, which shows the oil-free centrifugal compressor (ITRI model MBC-250, R-134a) with the inverter control (ReymeBus RM6P1-4250E3)—-the revolution is detected by a magnetic bearing sensor, which shows a slip deviation to be less than $1 \%$ against the inverter controller-a shell-and-tube condenser, an electrical expansion valve (Danfoss ETS-4000), and an evaporator with a shell-and-tube configuration. A level sensor is used to measure the condensate level within the condenser (PAL PVLS-250, range 0-250 $\mathrm{mm}$, sensing resolution $6 \mathrm{~mm}$ ). The nominal capacities of the centrifugal chillers are 200 USRT (falling-film type, $703 \mathrm{~kW}$ ), and 230 USRT (flooded type, $809 \mathrm{~kW}$ ), respectively. Both chillers are incorporated with the same oil-free compressor and R-134a is used as the working fluid. The maximum refrigerant flowrate is $5.46 \mathrm{~kg} / \mathrm{s}$. The dimensions of the falling film evaporator and flooded evaporator are shown in Figure 2. Both evaporators adopt a 2-pass arrangement. The shell diameter for the falling-film evaporator is $670 \mathrm{~mm}$, and $680 \mathrm{~mm}$ for the flooded evaporator. The test tubes are made from Wieland GEWA

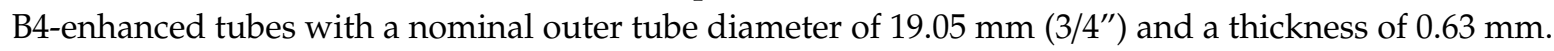


The tube length of each tube for both evaporators is $3 \mathrm{~m}$. The evaporator is insulated carefully and the heat loss to the ambient is estimated to be less than $0.5 \%$ of the nominal capacity.

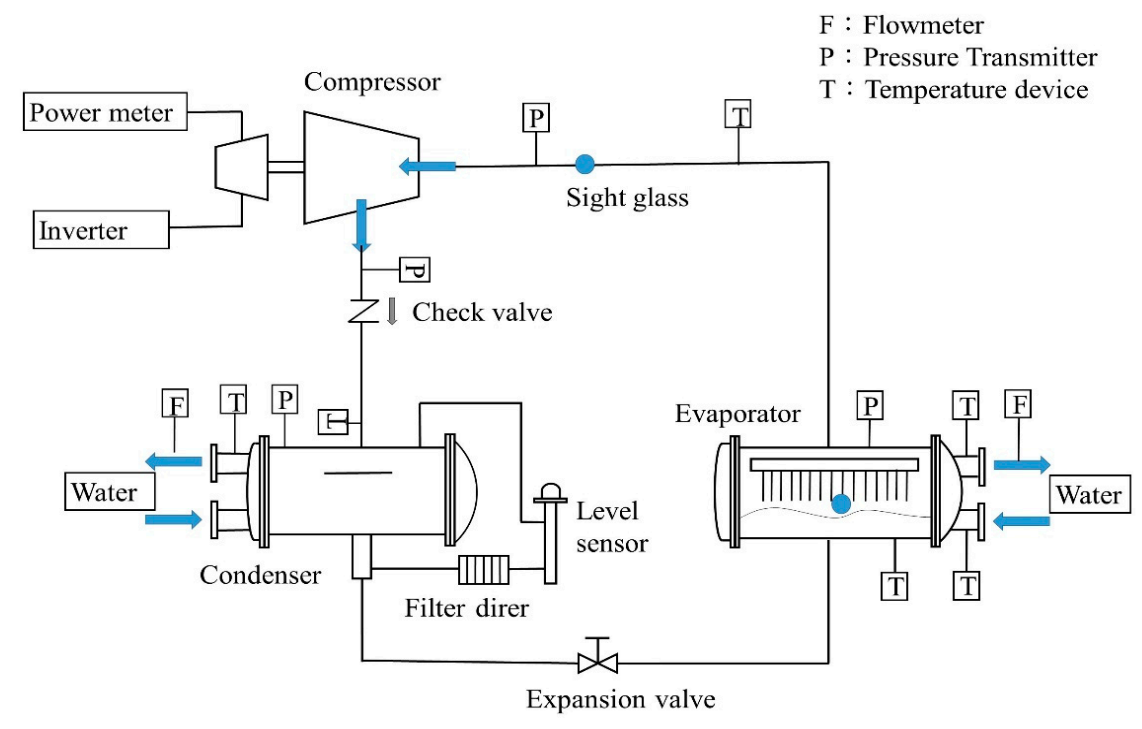

Figure 1. Schematic of the test facilty.

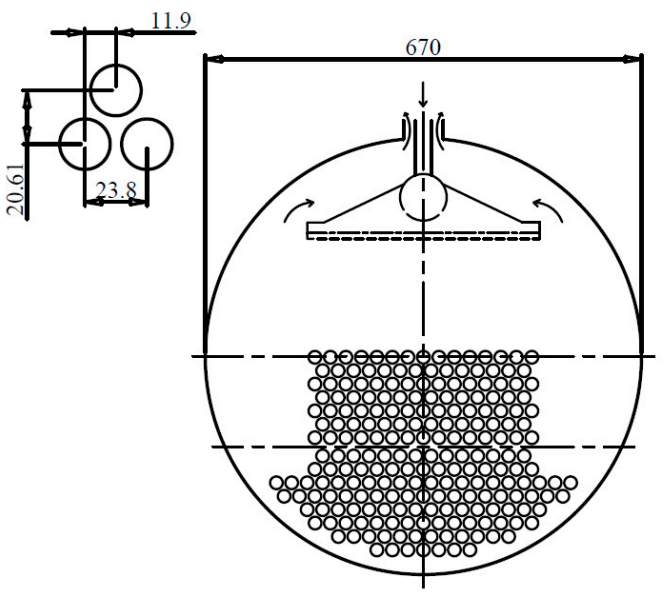

(a) Falling film evaporator

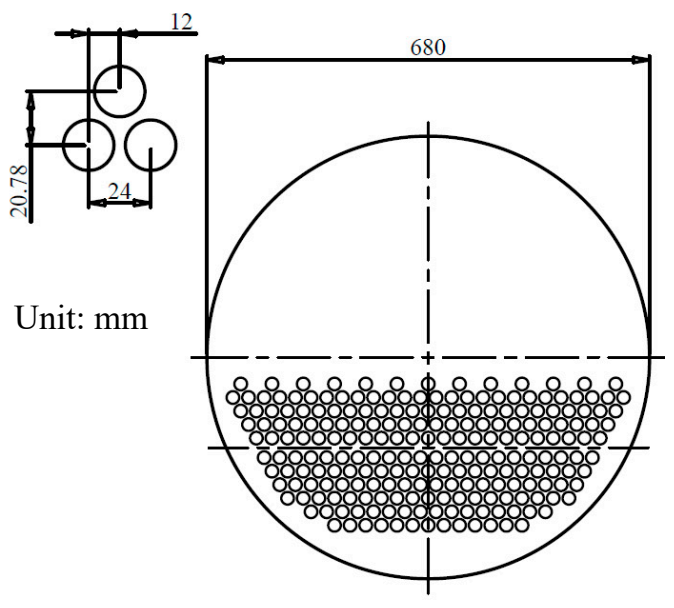

(b) flooded evaoprator

Figure 2. Tube bundle for the falling-film evaporator and the flooded evaporator (unit: $\mathrm{mm}$ ).

\subsection{Experimental Apparatus and Measurements}

To ensure the accurate measurements and fair comparisons, tests are conducted following the and AHRI standard 551/591(SI) [2]. The refrigerant inventory for the falling-film evaporator and the flooded evaporator are $220 \mathrm{~kg}$ and $250 \mathrm{~kg}$, respectively. The refrigerant charge is based on the nominal rating at full load. Based on the standard requirement, the following test conditions are carried out:

1. Chilled water flowrate at the evaporator: the flowrate at full-load operation for both chillers is regulated to achieve a fixed temperature difference of chilled water across the evaporator $\left(5^{\circ} \mathrm{C}\right.$, with tolerance being less than $0.3^{\circ} \mathrm{C}$ ). The required water flowrate is about $10 \mathrm{LPM}$ per USRT (2.84 LPM per $\mathrm{kW})$.

2. Cooling water flowrate at the condenser: the flowrate at full-load operation for both chillers is regulated to achieve a fixed temperature difference of cooling water across the condenser $\left(5^{\circ} \mathrm{C}\right.$, with tolerance being less than $0.3^{\circ} \mathrm{C}$ ). The required water flowrate is about $12.5 \mathrm{LPM}$ per USRT (3.56 LPM per kW). 
3. Outlet temperature of the chilled water: the temperature is required to be maintained at $7^{\circ} \mathrm{C}$ with $0.3{ }^{\circ} \mathrm{C}$ tolerance.

4. Inlet temperature of the cooling water: tests are conducted in different loading conditions $(100 \%$, $75 \%, 50 \%$ and $25 \%$ ). The corresponding temperatures to arrive at the loading are $30^{\circ} \mathrm{C}, 24.5^{\circ} \mathrm{C}$, $19.0^{\circ} \mathrm{C}$, and $19.0^{\circ} \mathrm{C}$, respectively, with a tolerance of $0.3^{\circ} \mathrm{C}$.

A magnetic flowmeter (Yokogawa, model SE220MJ with a resolution of $0.5 \%$ ) of the chilled water is installed at the water return, as shown in Figure 1. The inlet and outlet temperatures of the evaporator and the condenser are measured by calibrated RTD (Resistance Temperature Device, OMEGA Pt100) with a resolution of $0.1{ }^{\circ} \mathrm{C}$. The corresponding evaporation pressure and condensing pressure is measured by pressure transmitter (WIKA R-1) with a calibrated accuracy of $2 \%$. The consumed power of the compressor is measured by Yokogawa WT230 power meter, which has an accuracy of $0.5 \%$.

\subsection{Data Reduction of the Experimental Measurements}

The capacity of the water chiller is calculated by

$$
\dot{Q}=\dot{m}_{\text {eva,water }} c_{p, w a t e r} \Delta T_{\text {eva,water }}
$$

where $\dot{m}_{e v a, \text { water }}$ is the chilled water flowrate, $c_{p, \text { water }}$ is the specific heat of chilled water, and $\Delta T_{\text {eva,water }}$ is the temperature difference of chilled water at the evaporator. The corresponding coefficient of performance (COP) is calculated as

$$
C O P=\frac{\dot{Q}}{W_{\text {comp }}}
$$

where $W_{\text {comp }}$ is the power consumption of the compressor. The integrated part load value (IPLV) can be calculated from Equation (1). The effectiveness of the evaporator is calculated as:

$$
\varepsilon \equiv \frac{\dot{Q}}{\dot{Q}_{\max }}=\frac{\dot{Q}}{C_{\min }\left(T_{\text {in,water }}-T_{\text {sat }, e v a}\right)}
$$

For the phase change heat exchanger like the present falling film evaporator or flooded evaporator, $C_{\min }=\dot{m}_{e v a, w a t e r} c_{p, w a t e r}$, and the effectiveness is only a function of the number of transfer unit $(N T U)$,

$$
N T U \equiv U A / C_{\min }
$$

As a result,

$$
\varepsilon=1-e^{-N T U}
$$

Hence, the NTU can be derived from the measurements to obtain the overall heat transfer conductance $(U A)$ or the overall heat transfer coefficient $U$. Note that the overall heat transfer coefficient in this study is based on the outer surface of the tube.

\section{Results and Discussion}

Table 1 shows the test results for the centrifugal water chillers. Note that these two test chillers contain the same compressor. Although the compressor is the same for these two chillers, the nominal capacity for the flooded type is 230 USRT $(809 \mathrm{~kW})$, while the falling film evaporator contains a $200 \mathrm{RT}$ $(703 \mathrm{~kW})$ chiller capacity. Both chillers reveal an appreciable drop of capacity and compressor power when the compressor revolution is reduced. However, the corresponding COP rises when the loading is reduced and reaches the plateau at 50\% part-load with a COP of around 9.9. A further un-loading to $25 \%$ leads to a detectable decline of the COP. Basically, the system performance subject to part-load is similar to the test results for the compressor from the calorimeter. Yet the corresponding IPLV for the falling film evaporator is 8.627 while it is 8.634 . Basically, the system performance for both systems is 
about the same both in full-loading and in partial loading conditions. There is barely any difference as far as system performance is concerned.

Table 1. Test results for the oil-free centrifugal chiller with a falling evaporator and a flooded evaporator associated with full and partial loading.

\begin{tabular}{|c|c|c|c|c|c|c|c|c|}
\hline \multirow{2}{*}{$\frac{\text { Type of Evaporator }}{\text { Loading }}$} & \multicolumn{4}{|c|}{ Falling Film EVA } & \multicolumn{4}{|c|}{ Flooded EVA } \\
\hline & $100 \%$ & $75 \%$ & $50 \%$ & $25 \%$ & $100 \%$ & $75 \%$ & $50 \%$ & $25 \%$ \\
\hline EEV opening (\%) & 56 & 43 & 33 & 20 & 93 & 60 & 48 & 37 \\
\hline Inverter frequency $(\mathrm{Hz})$ & 605 & 517 & 428 & 408 & 625 & 535 & 439 & 417 \\
\hline Rpm & 18,150 & 15,510 & 12,840 & 12,240 & 18,750 & 16,050 & 13,170 & 12,510 \\
\hline Compression ratio & 2.49 & 2.00 & 1.63 & 1.56 & 2.52 & 2.04 & 1.64 & 1.57 \\
\hline Capacity (USRT) & 198.7 & 149.0 & 101.4 & 51.0 & 229.9 & 169.3 & 112.2 & 58.6 \\
\hline Capacity $(\mathrm{kW})$ & 698.7 & 524.0 & 356.5 & 179.3 & 808.5 & 595.1 & 394.5 & 206.1 \\
\hline Suction pressure (bar, gage) & 2.62 & 2.65 & 2.69 & 2.69 & 2.61 & 2.63 & 2.67 & 2.68 \\
\hline Discharge pressure (bar, gage) & 8.05 & 6.3 & 5.03 & 4.75 & 8.12 & 6.41 & 5.02 & 4.77 \\
\hline Chilled water flowrate (LPM) & 2018 & 2018 & 2018 & 2018 & 2322 & 2322 & 2322 & 2322 \\
\hline $\begin{array}{l}\text { Inlet temperature } \\
\text { Chilled water }\left({ }^{\circ} \mathrm{C}\right)\end{array}$ & 12.3 & 11.0 & 9.8 & 8.5 & 12.1 & 10.7 & 9.6 & 8.3 \\
\hline $\begin{array}{l}\text { Outlet temperature } \\
\text { Chilled water }\left({ }^{\circ} \mathrm{C}\right)\end{array}$ & 7.3 & 7.3 & 7.3 & 7.2 & 7.2 & 7.1 & 7.1 & 7.1 \\
\hline Cooling water flowrate (LPM) & 2551 & 2551 & 2551 & 2551 & 2796 & 2796 & 2796 & 2796 \\
\hline $\begin{array}{l}\text { Inlet temperature } \\
\text { Cooling water }\left({ }^{\circ} \mathrm{C}\right)\end{array}$ & 29.8 & 23.9 & 18.9 & 18.8 & 29.8 & 24.5 & 19.1 & 18.9 \\
\hline $\begin{array}{l}\text { Outlet temperature } \\
\text { Cooling water }\left({ }^{\circ} \mathrm{C}\right)\end{array}$ & 34.4 & 27.2 & 21.1 & 19.9 & 34.4 & 27.9 & 21.3 & 20.1 \\
\hline $\mathrm{COP}$ & 5.54 & 7.51 & 9.94 & 7.87 & 5.58 & 7.35 & 9.99 & 8.3 \\
\hline Power $(\mathrm{kW})$ & 126.08 & 69.77 & 35.86 & 22.79 & 144.9 & 80.97 & 39.15 & 24.85 \\
\hline Evaporation pressure (bar, gage) & 2.66 & 2.67 & 2.70 & 2.68 & 2.72 & 2.70 & 2.71 & 2.71 \\
\hline Evaporation Temperature $\left({ }^{\circ} \mathrm{C}\right)$ & 6.4 & 6.5 & 6.7 & 6.7 & 6.9 & 6.7 & 6.8 & 6.8 \\
\hline Condensing pressure (bar, gage) & 7.99 & 6.19 & 4.97 & 4.72 & 7.81 & 6.32 & 5.00 & 4.77 \\
\hline Condensing Temperature $\left({ }^{\circ} \mathrm{C}\right)$ & 35.2 & 27.5 & 21.3 & 20.0 & 34.5 & 28.1 & 21.5 & 20.2 \\
\hline Discharge Temperature $\left({ }^{\circ} \mathrm{C}\right)$ & 42.6 & 33.4 & 25.9 & 25.9 & 42.7 & 34.1 & 26.0 & 26.3 \\
\hline
\end{tabular}

On the other hand, the corresponding overall heat transfer coefficient (based on outer wall surface area) vs. the heat flux for both the flooded and the falling-film evaporator is shown in Figure 3. Apparently, the overall heat transfer coefficient increases with the rise of loading. Normally, the overall heat transfer coefficient for the flooded type evaporator is about $30 \sim 40 \%$ higher than the falling film evaporator. Notice that the mean temperature and the chilled water flowrate in the tube side for both evaporators remains the same for both evaporators. Yet the tube pass is the same and the tube number in each pass for the flooded evaporator is about the same as that of the falling evaporator. A quick estimate shows that the dominant thermal resistance is on the shell side (about $60-75 \%$ ). Hence, the thermal resistance on the tube side for the flooded evaporator is roughly the same as that of the falling film evaporator, indicating that the difference in overall heat transfer performance is due to the difference in the heat transfer coefficient on the shell side rather than on the tube side. Note that some prior studies indicated that the falling evaporation contains a better heat transfer performance than the pure nucleate boiling mode (e.g., $[12,13,18])$. Hence, it is expected that the falling evaporator should yield a higher overall heat transfer performance, since heat transfer mode for both evaporation and nucleate boiling take place in the tube bundle. Yet, as explained by Christians and Thome [19], the presence of the falling film on the enhanced tubes could result in a low-pressure zone that entrains the bubble more efficiently from the pores, thereby revealing superior heat transfer performance for the falling film evaporator when compared with the flooded evaporator. However, surprisingly, in this study, the flooded evaporator outperforms the falling evaporator as far as overall heat transfer coefficient is concerned, as shown in Figure 3. Yet the difference in overall heat transfer coefficient 
between the flooded evaporator and the falling film becomes even more pronounced when the loading is increased. In the practical falling film evaporator, the falling film can be made available either by spraying or trickling to distribute liquid refrigerant on the bundles [16]. The falling film evaporators with spraying distribution usually require refrigerant pumps to fulfill the sprayed liquid cycle and the amount of recirculated refrigerant normally exceeds the evaporated mass among the bundles. Hence, most falling film evaporators incorporate trickling design for easier maintenance [16]. Note that the present enhanced surface is the Wieland GEWA B tubing, and the surface reveals a different heat transfer behavior against heat flux for a nucleate boiling condition. For a heat flux below $20 \mathrm{~kW} / \mathrm{m}^{2}$, the corresponding heat transfer coefficient increases with the rise of heat flux. Conversely, a detectable decline is seen when the heat flux surpasses the threshold value [20]. In the present tests, the maximum heat flux is around $20 \mathrm{~kW} / \mathrm{m}^{2}$ at full-load and ranges around $5 \sim 15 \mathrm{~kW} / \mathrm{m}^{2}$ at partial load. This suggests a positive influence of heat flux upon HTCs in the present flooded evaporator. Notice that the overall thermal resistance is related to in-tube water side resistance, wall resistance, and shell side resistance in the following:

$$
\frac{1}{U_{o}}=\frac{1}{h_{o}}+\frac{\ln \left(\frac{D_{o}}{D_{i}}\right)}{2 \pi k_{w} L}+\frac{A_{o}}{h_{i} A_{i}}
$$

where $U_{0}$ is the overall heat transfer coefficient, and $h_{i}$ and $h_{0}$ are the heat transfer coefficient in the tube side and shell side, respectively. $k_{w}$ is the thermal conductivity of the tube material, and $A_{o}$ and $A_{i}$ represent the surface area in the shell and tube side, respectively. $L$ is the length of the test tube. The test is conducted at identical water flowrate for all loadings and the variation in chilled water temperature is also small, thereby suggesting a nearly constant HTC at the chilled water side throughout the tests. This is applicable both in full loading and partial loading. Yet the wall resistance remains unchanged during the tests. As a consequence,

$$
\frac{1}{U_{o}}=\frac{1}{h_{o}}+C_{0}
$$

where $C_{0}=\frac{\ln \left(\frac{D_{o}}{D_{i}}\right)}{2 \pi k_{w} L}+\frac{A_{o}}{h_{i} A_{i}}$. In the meantime, $h_{0} \sim C_{1} q^{n}$ for the HTC in the shell side is subject to nucleate boiling as long as the heat transfer is below the threshold heat flux [8]. Hence,

$$
\frac{1}{U_{o}}=\frac{1}{C_{1}} q^{-n}+C_{0}=C_{2} X+C_{0}
$$




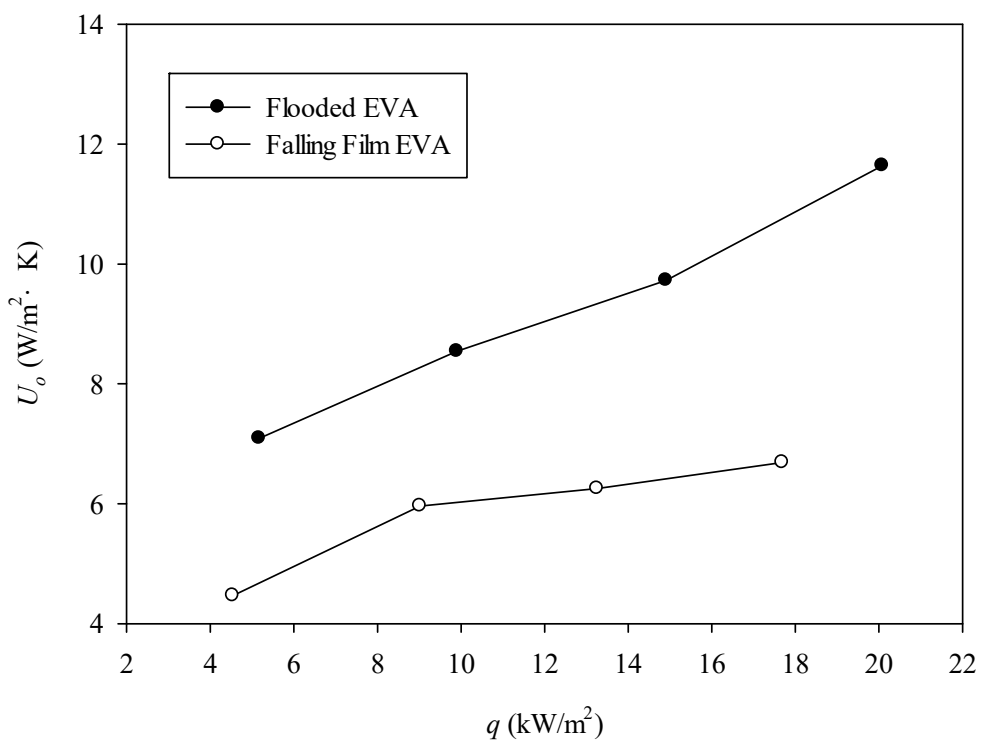

Figure 3. The overall heat transfer coefficient $U$ vs. heat flux for the falling film evaporator and the flooded evaporator.

A simple linear regression analysis indicates that $n \sim 0.45$ for the present flooded evaporator while the intercept $C_{0}$ is equal to $0.028 \mathrm{~m}^{2} \cdot \mathrm{K} / \mathrm{kW}$. Note that the corresponding $\mathrm{R}^{2}$ value for the regression is 0.972. In this regard, the corresponding HTC of the tube bundle can be obtained by manipulating the reciprocal of Equation (9):

$$
h_{0}=\frac{1}{\frac{1}{U_{0}}-C_{0}}
$$

Based on the foregoing analysis, the corresponding HTC for the flooded evaporator at full, $75 \%, 50 \%$, and $25 \%$ loading are $14.1,13.3,11.2$, and $8.9 \mathrm{~kW} / \mathrm{m}^{2} \cdot \mathrm{K}$, respectively. On the other hand, as depicted in Figure 3, the overall heat transfer coefficient for the falling film evaporator is appreciably lower than that of the flooded evaporator. There are two reasons for the worse performance of the present falling film evaporator when compared with the flooded evaporator. Note that the falling film evaporator contains two heat transfer modes, namely the evaporation at the liquid/vapor interface and the nucleate boiling at the tube wall surface. Commonly, the contribution of nucleate boiling surpasses the evaporation. A typical HTC distribution associated with tube location (from the first tube to the ninth tube) for the enhanced tube bundle vs. the film Reynolds number by Roques and Thome is shown in Figure 4a [8]. Notice that their test is conducted via GEWA-B enhanced tubes, which are the same as the present test tubes. Apparently, the HTC is strongly related to the film Reynolds number. Note that the Reynolds number is defined as:

$$
\operatorname{Re}=\frac{4 \Gamma}{\mu}
$$

where $\Gamma$ is the liquid flowrate on one side of the tube per unit length. When the film Reynolds number is below a certain threshold value (around 200), the HTC increases with the rise of the film Reynolds number, and the HTC remains barely unchanged with the heat flux. This phenomenon prevails for all the tube locations. The results suggest that evaporation is in control. Analogously, Zhao et al. [12] also performed tests on an enhanced tube bundle using R-134a as the working fluid. Their results, shown in Figure $4 \mathrm{~b}$, also indicated that the HTC increases with the film flowrate before a threshold film flowrate of around $0.02 \mathrm{~kg} / \mathrm{m} \cdot \mathrm{s}$, and that the HTC is relatively independent of heat flux. On the other hand, once the film flowrate or Reynolds number exceeds the threshold value, the HTC remains roughly unchanged with the film flowrate. Although the HTC is quite independent of the film flowrate after the threshold value, it is appreciably increased with the rise of heat flux when passing the threshold 
value. The results indicate that the nucleate boiling plays an essential role when the film flowrate is above the threshold value. Note that in this study, the corresponding average Reynolds number for the falling film evaporator in the first row spans at around 70 285 and the maximum film flowrate ranges from $0.004 \sim 0.015 \mathrm{~kg} / \mathrm{m} \cdot \mathrm{s}$. The results are close to or below the threshold value of the film Reynolds number and the film flowrate, thereby indicating the dominance of evaporation. In the meantime, as depicted in Figure 2a regarding the layout of the falling film evaporator, which contains a 15 tube row, the effective mean film flowrate in the middle or bottom part of the falling film evaporator may show a much lower liquid film flowrate than the upper portion. Thus, the loss of film flowrate in the middle and bottom part of the tube bundle may bring out dry patches on the tube and deteriorate the heat transfer accordingly. Note that the dry-out patch and the very thin liquid film on the enhanced tube may jeopardized the nucleate boiling mode considerably. In essence, the effective decline of the film flowrate from the top tube toward the bottom part of the falling film evaporator renders an appreciably lower overall HTC when compared with the flooded evaporator. The onset of dry-out of the falling evaporator was also investigated in prior studies. For example, Christians and Thome [21] reported the onset of dry-out Reynolds numbers for the falling film evaporator with enhanced tubes (Turbo B5 and GEWA B5) subject to R-134a and R-236fa. Christians and Thome [19] developed an empirical correlation for the onset of dry-out of falling film, i.e.,

$$
\operatorname{Re}_{\text {onset }}=20.721\left(\frac{q_{o}}{h_{l v} \mu_{\text {ref }}}\right)^{1.04} G_{t-s}^{0.175}
$$

where $G_{t-s}$ is the tube specific number, which is 0.1777 for the GEWA B tube. $h_{l v}$ is the latent heat of evaporation. Based on the calculations from this formula, the onset of the dry-out Reynolds number ranges from 34 (25\% loading) to 137 (full loading). The results imply that the onset of dry-out can easily occur when the row number is in the middle or bottom portion of the tube bundle. Basically, the present data for the falling film evaporator are expected to contain certain dry-out patches according to their onset of dry-out diagram. It is likely that the local HTC in the upper part of the falling evaporator may still be higher than the corresponding flooded evaporator, but the middle and bottom part of the falling film evaporator may suffer a much lower HTC due to dry patches, thereby resulting in a much lower overall HTC, even at full loading operation. To make the operation even worse, the overall HTC for the falling film evaporator shows an appreciable dip at a partial loading $(25 \%)$, as seen in Figure 3, compared to the flooded evaporator. In fact, the film flowrate in the bottom row may even fall below $0.001 \mathrm{~kg} / \mathrm{m} \cdot \mathrm{s}$, indicating a considerable starvation of the liquid film flowrate on the enhanced tubes. Note that the flooded evaporator does not reveal such a dramatic decline in the overall HTC since the refrigerant level is always above the top tube. The results are in line with the numerical simulation regarding the influence of dry patch on the falling film evaporator by Yang et al. [17], who concluded that the heat transfer performance of falling evaporators can be enhanced by increasing the refrigerant flowrate within a certain range due to the decreasing dry patch areas on falling film tubes, and the evaporators reach the best thermal performance when no dry patches appear on the tube. Yet, the deterioration can be further accentuated with mal distribution from the distributor, as addressed by Yang et al. [17]. In summary of the foregoing discussion, it is quite likely that the present falling film evaporator may contain superfluous tubes. The overall performance may still be the same by removing some tubes located in the middle and the bottom part of the tube bundle. 


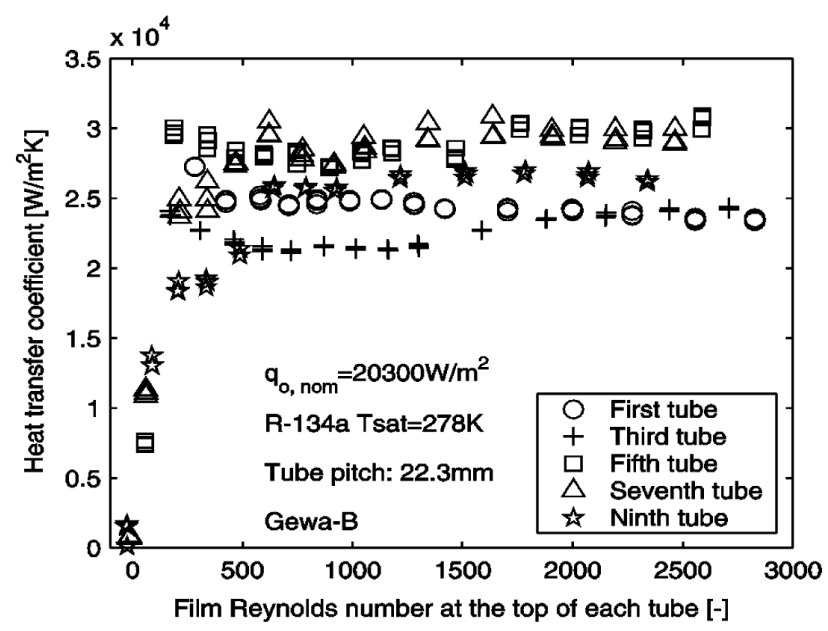

(a) Influence of tube position on the heat transfer coefficient (HTC) [8]

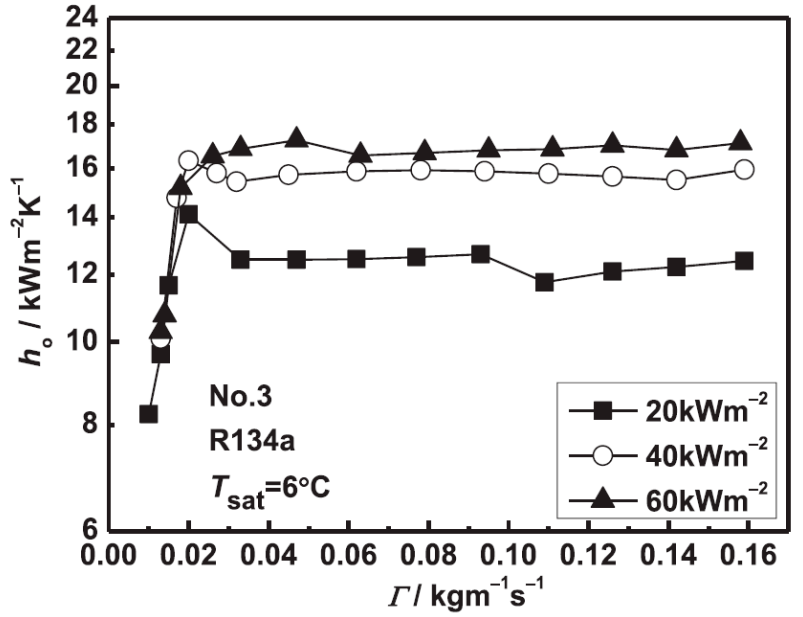

(b) Effect of film flowrate on the HTC subject to heat flux [12]

Figure 4. Trend of HTCs subject to tube position and heat flux for the falling film evaporator with R-134a. Figure 4a Reprinted with permission from [8]. Copyright 2007 Taylor and Francis; Figure 4b Reprinted with permission from [12]. Copyright 2017 Elsevier.

\section{Conclusions}

The present study compares the performance of real-scale oil-free centrifugal chillers with a flooded evaporator and a falling film evaporator. The nominal capacity for the test chillers is around 200 220 RT. The compressors of the two chillers are identical. Both evaporators make use of GEWA-B-enhanced tubes and R-134a is used as the working fluid. Tests were conducted in full, $75 \%, 50 \%$, and $25 \%$ loading. Based on the forgoing discussions, the following conclusions are derived:

1. Both chillers reveal an appreciable drop of capacity and compressor power when the compressor revolution is reduced but the corresponding COP rises when the loading is reduced, and it reaches the plateau at $50 \%$ part-load with a COP of around 9.9. A further un-loading to $25 \%$ leads to a detectable decline of COP.

2. The system performance in terms of IPLV for the falling film evaporator is 8.627 and it is 8.634 for the flooded evaporator, implying a comparable performance between the falling film evaporator and the flooded evaporator.

3. The overall heat transfer coefficient for the flooded evaporator is appreciably higher than the falling film evaporator by up to $40 \%$. The results do not agree with typical test results on falling film evaporators and flooded evaporators. This is because the falling film flowrate is below the threshold value and the heat transfer is dominated by the evaporation mode. Yet, the heat transfer 
performance for the falling film evaporator can be further jeopardized due to starvation of the film flowrate (partial dry-out), since the present film flowrate may fall below the threshold critical film flowrate, especially in the middle or bottom of the tube bundle. This phenomenon becomes even more pronounced at partial loading $(25 \%)$, while the flooded evaporator did not reveal such performance dip at partial loading.

Author Contributions: All the authors have contributed their efforts to complete the paper. K.-S.H. prepared and analyzed the data, J.-C.C. and J.-J.L. conducted the experiments, C.-C.L. supervised the project and C.-C.W. wrote and edited the manuscript.

Funding: This research was funded by Ministry of Economics Affairs, Taiwan and grants from Ministry of Science and Technology, Taiwan under grant numbers 107-2622-E-009-011-CC2 and 108-2622-E-009-004-CC2.

Conflicts of Interest: The authors declare no conflict of interest.

\section{Nomenclature}

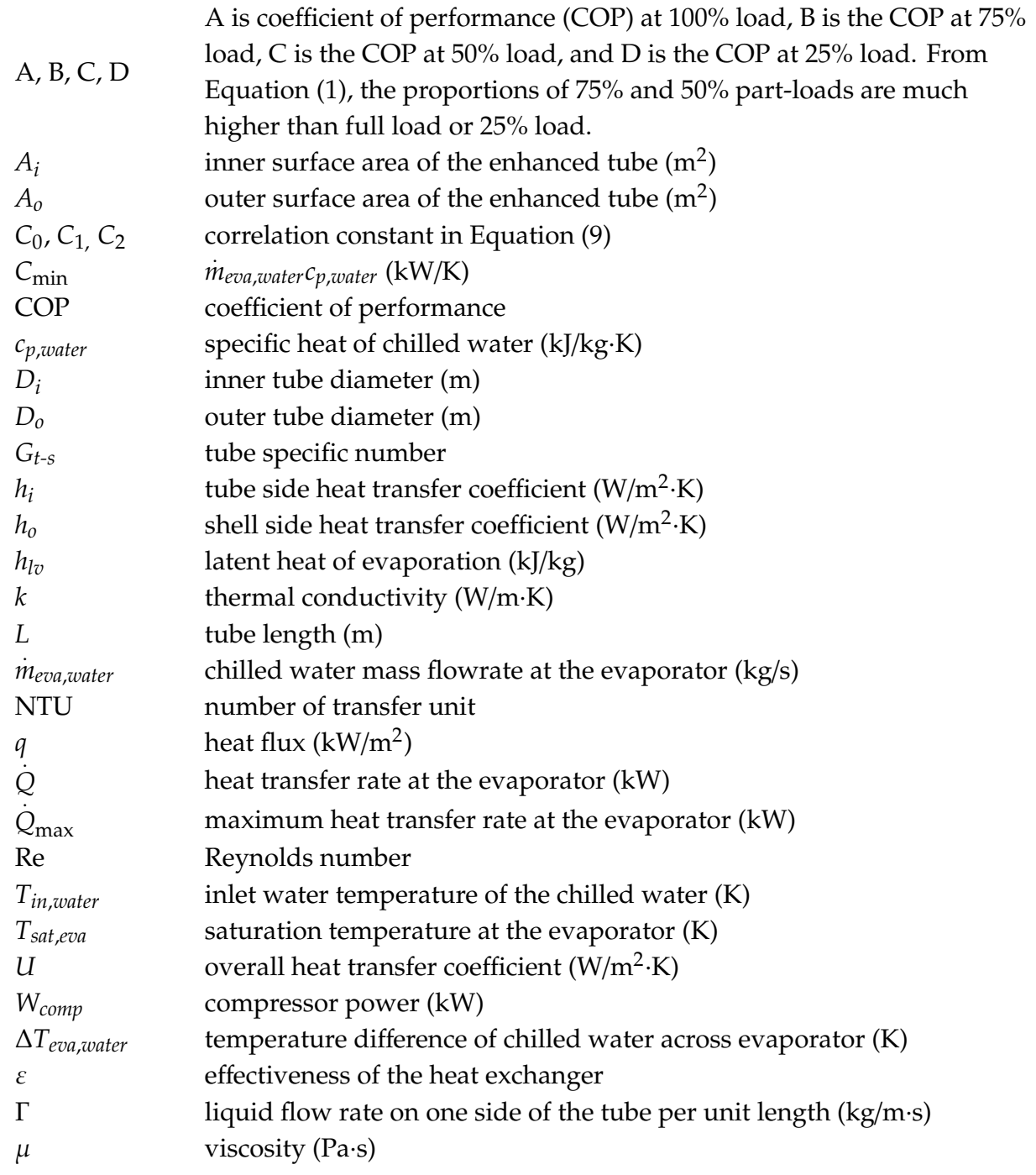

\section{References}

1. Hung, K.-S.; Chung, J.-C.; Liu, C.-C.; Huang, J.-M. A study of off-design performance improvement for a centrifugal refrigerant compressor. Adv. Mech. Eng. 2017, 9. [CrossRef]

2. Air-Conditioning, Heating, and Refrigeration Institute (AHRI). Performance Rating of Water-chilling and Heat Pump Water-heating Packages Using the Vapor Compression Cycle. In ANSI/AHRI STANDARD 551/591 (SI)-2018; AHRI: Arlington, VA, USA, 2018. 
3. Yu, F.W.; Chan, K.T.; Sit, R.K.Y. Analysis of centrifugal chillers with oil-free magnetic bearings for enhancing building energy performance. Sci. Technol. Built Environ. 2017, 23, 334-344. [CrossRef]

4. Yu, F.W.; Chan, K.T.; Sit, R.K.Y.; Yang, J. Performance Evaluation of Oil-free Chillers for Building Energy Performance Improvement. Procedia Eng. 2015, 121, 975-983. [CrossRef]

5. Lissandrin, M.; Rampazzo, M.; Cecchinato, L.; Beghi, A. Optimal operational efficiency of chillers using oil-free centrifugal compressors. Int. J. Refrig. 2017, 82, 83-96. [CrossRef]

6. Wang, C.-C.; Hafner, A.; Kuo, C.-S.; Hsieh, W.-D. An overview of the effect of lubricant on the heat transfer performance on conventional refrigerants and natural refrigerant R-744. Renew. Sustain. Energy Rev. 2012, 16, 5071-5086. [CrossRef]

7. Wang, C.-C.; Hafner, A.; Kuo, C.-S.; Hsieh, W.-D. Influence of Lubricant on the Nucleate Boiling Heat Transfer Performance of Refrigerant-A Review. Heat Transf. Eng. 2014, 35, 651-663. [CrossRef]

8. Roques, J.F.; Thome, J.R. Falling Films on Arrays of Horizontal Tubes with R-134a, Part I: Boiling Heat Transfer Results for Four Types of Tubes. Heat Transf. Eng. 2007, 28, 398-414. [CrossRef]

9. Roques, J.F.; Thome, J.R. Falling Films on Arrays of Horizontal Tubes with R-134a, Part II: Flow Visualization, Onset of Dryout, and Heat Transfer Predictions. Heat Transf. Eng. 2007, 28, 415-434. [CrossRef]

10. Habert, M.; Thome, J.R. Falling-Film Evaporation on Tube Bundle with Plain and Enhanced Tubes-Part I: Experimental Results. Exp. Heat Transf. 2010, 23, 259-280. [CrossRef]

11. Habert, M.; Thome, J.R. Falling-Film Evaporation on Tube Bundle with Plain and Enhanced Tubes-Part II: New Prediction Methods. Exp. Heat Transf. 2010, 23, 281-297. [CrossRef]

12. Zhao, C.-Y.; Jin, P.-H.; Ji, W.-T.; He, Y.-L.; Tao, W.-Q. Experimental investigations of R134a and R123 falling film evaporation on enhanced horizontal tubes. Int. J. Refrig. 2017, 75, 190-203. [CrossRef]

13. Jin, P.-H.; Zhao, C.-Y.; Ji, W.-T.; Tao, W.-Q. Experimental investigation of R410A and R32 falling film evaporation on horizontal enhanced tubes. Appl. Therm. Eng. 2018, 137, 739-748. [CrossRef]

14. Ji, W.-T.; Zhao, C.-Y.; Zhang, D.-C.; Yoshioka, S.; He, Y.-L.; Tao, W.-Q. Effect of vapor flow on the falling film evaporation of R134a outside a horizontal tube bundle. Int. J. Heat Mass Transf. 2016, 92, 1171-1181. [CrossRef]

15. Van Rooyen, E.; Thome, J.R. Flow boiling data and prediction method for enhanced boiling tubes and tube bundles with R-134a and R-236fa including a comparison with falling film evaporation. Int. J. Refrig. 2014, 41, 60-71. [CrossRef]

16. Yang, L.; Wang, W. The heat transfer performance of horizontal tube bundles in large falling film evaporators. Int. J. Refrig. 2011, 34, 303-316. [CrossRef]

17. Yang, L.; Song, X.; Xie, Y. Effect of the Dryout in Tube Bundles on the Heat Transfer Performance of Falling Film Evaporators. Procedia Eng. 2017, 205, 2176-2183. [CrossRef]

18. Ribatski, G.; Jacobi, A.M. Falling-film evaporation on horizontal tubes-A critical review. Int. J. Refrig. 2005, 28, 635-653. [CrossRef]

19. Christians, M.; Thome, J.R. Falling film evaporation on enhanced tubes, part 2: Prediction methods and visualization. Int. J. Refrig. 2012, 35, 313-324. [CrossRef]

20. Van Rooyen, E.; Thome, J.R. Pool boiling data and prediction method for enhanced boiling tubes with R-134a, R-236fa and R-1234ze(E). Int. J. Refrig. 2013, 36, 447-455. [CrossRef]

21. Christians, M.; Thome, J.R. Falling film evaporation on enhanced tubes, part 1: Experimental results for pool boiling, onset-of-dryout and falling film evaporation. Int. J. Refrig. 2012, 35, 300-312. [CrossRef]

(C) 2019 by the authors. Licensee MDPI, Basel, Switzerland. This article is an open access article distributed under the terms and conditions of the Creative Commons Attribution (CC BY) license (http://creativecommons.org/licenses/by/4.0/). 